\title{
WIDTH OF THE GREAT SAPHENOUS VEIN LUMEN IN THE GROIN AND OCCURENCE OF SIGNIFICANT REFLUX IN THE SAPHENO-FEMORAL JUNCTION
}

\author{
Dalibor Musila*, Jiri Herman ${ }^{\mathrm{b}}$, Julius Mazuch ${ }^{\mathrm{c}}$ \\ a Vascular Ambulance and Department of Pathophysiology, Palacky University Olomouc, Czech Republic \\ $2^{\text {nd }}$ Department of Surgery, Palacky University Olomouc \\ $1^{\text {st }}$ Department of Surgery, Jessenius University Martin, Slovakia \\ e-mail:musil.dalibor@quick.cz
}

Received: September 18, 2008; Accepted: November 15, 2008

Key words: Great saphenous vein (GSV)/Sapheno-femoral junction (SFJ)/Duplex sonography/Reflux/Width of the lumen of $G S V$

Aim: This study was performed to assess the contribution of the width of the anechogenous lumen of the great saphenous vein (GSV) in the groin measured by ultrasound (US) to the diagnostics of haemodynamically significant reflux (HSR) in the sapheno-femoral junction (SFJ).

Methods: We examined 200 lower limbs with primary varicose veins in 182 patients. Duplex scanning was performed with the patients in the supine position. Longitudinaly imaging (B-mode) the inner anechogenous diameter of GSV was measured 4-5 cm distal to SFJ. PW Doppler sampling volume was placed at the same distance. The reflux was elicited by Valsalve manoeuvre. The HSR was defined as a backflow lasting $\geq 1 \mathrm{~s}$ with a velocity of $\operatorname{Vmax} \geq 10 \mathrm{~cm} / \mathrm{s}$.

Results: The mean width of the GSV with HSR ( $\mathrm{n}=152)$ was $6.39 \mathrm{~mm}$, median $6.0 \mathrm{~mm}, \mathrm{SD} \pm 2.21 \mathrm{~mm}$. The mean width of GSV without HSR $(\mathrm{n}=48)$ was $4.41 \mathrm{~mm}$, median $4.4 \mathrm{~mm}, \mathrm{SD} \pm 0.96 \mathrm{~mm}$. The difference between the mean widths of GSV was statistically significant ( $p<0.01)$. In GSV $<5 \mathrm{~mm}(\mathrm{n}=77) \mathrm{HSR}(\mathrm{V} \max \geq 10 \mathrm{~cm} / \mathrm{s})$ was confirmed in 46 cases $(59.7 \%)$, in GSV $\geq 5 \mathrm{~mm}(\mathrm{n}=123)$ in 106 cases $(86.2 \%)$. The sensitivity of dilatation of GSV $\geq 5 \mathrm{~mm}$ for the presence of HSR in SFJ was $69.7 \%$, specificity $64.6 \%$. PPV (positive predictive value) of dilatation of GSV $\geq 5 \mathrm{~mm}$ for the presence of HSR in SFJ was $86.2 \%$, NPV (negative predictive value) was $40.3 \%$, and the diagnostic accuracy of dilatation of GSV $\geq 5 \mathrm{~mm}$ was $68.5 \%$.

Conclusions: Measurement of anechogenous lumen GSV under the groin in B-mode is less sensitive $(69.7 \%)$ and less specific (64.6 \%) in the diagnostics of HSR in SFJ. Only $68.5 \%$ of all measurements of the width of the GSV below the groin in B-mode provided accurate indirect assessment of the functions of valves in SFJ. US scanning of the width of anechogenous lumen of GSV below the groin may serve only for ancillary examination.

\section{INTRODUCTION}

In ultrasound examination for venous insufficiency of the lower extremities we use duplex scanning to assess the function of venous valves and search for the reflux. Morphological evaluation of the vein in B-mode (when we focus on the measurement of the anechogenous venous lumen) is only secondary. In case of venous dilatation we consider venous insufficiency. Sometimes it is possible to scan venous valves, their motility and reaction to Valsalva manoeuvre or manual compression. However, minor venous valves are difficult to scan. The new generation of ultrasonographic devices makes it possible to follow their function and blood-flow under both physiological and pathological conditions ${ }^{12}$. In lower extremities with primary varicose veins we can observe insufficiency of the sapheno-femoral junction (SFJ) most frequently, ${ }^{75}$. The cause of trunk varices of the great saphenous vein (GSV) is reflux in the terminal and preterminal valves in the sapheno-femoral junction ${ }^{3}$. Recent work has already evaluated the relation between the width of GSV and the occurrence of the reflux in SFJ, and found a statistically significant correlation between the competence of the terminal valve and a GSV diameter of $<5 \mathrm{~mm}$ in the proximal third of the thigh $(p<0.001)$. When the GSV diameter was $6 \mathrm{~mm}$, an incompetent terminal valve was more likely $(\mathrm{p}<0.001)\left(\right.$ ref. $\left.^{4}\right)$.

The aim of this validation study was to objectively assess the usefulness of ultrasound scanning of the width of the GSV lumen in the diagnostics of reflux in SFJ. Specifically the objective was to assess the significance of ultrasound scanning of the width of the anechogenous GSV lumen in the groin in B-mode in the diagnostics of haemodynamically significant reflux in SFJ.

\section{MATERIALS AND METHODS}

We examined 200 lower extremities with primary varicose veins in 182 patients ( 125 women and 57 men, mean age $52 \pm 12$ years). The extremities were examined using duplex sonography for clinical manifestation of venous insufficiency of $\mathrm{C} 0-\mathrm{C} 6$, according to the CEAP classifi- 
cation. Duplex sonography (linear $10 \mathrm{MHz}$ probe, Logiq 5 Pro, General Electric Co.) was performed with patients in the supine position ${ }^{6,9}$.

In B-mode using longitudinal imaging, the measured inner anechogenous diameter of the GSV was 4-5 cm distally from SFJ and PW Doppler (Pulsed Wave Doppler) sample was placed at the same distance. The reflux was elicited by Valsalva manoeuvre presented for $5-10$ seconds, and was defined as a backflow lasting $\geq 1 \mathrm{~s}$ (ref. ${ }^{1,6,10,11}$ ). Haemodynamically significant reflux had a backflow velocity of Vmax $\geq 10 \mathrm{~cm} / \mathrm{s}$.

The examined great saphenous veins were subclassified according to the presence of haemodynamically significant reflux in SFJ into two groups: GSV with proven haemodynamically significant reflux $(\operatorname{Vmax} \geq 10 \mathrm{~cm} / \mathrm{s})$ and the GSV without haemodynamically significant reflux. In both groups we established maximum and minimum width of lumen and calculated means, medians and standard deviation (SD). The groups were compared using a t-test.

To objectively evaluate how useful measuring the width of the anechogenous lumen of the GSV is for haemodynamically significant reflux in SFJ, we used a contingency table (Table 2). The boundary width of anechogenous lumen of GSV was $5 \mathrm{~mm}$. Then we calculated sensitivity, specificity, positive predictive value, negative predictive value and diagnostic accuracy of the measurements of width of anechogenous lumen for hameodynamically significant reflux in the SFJ.

\section{RESULTS}

Haemodynamically significant reflux (Vmax $\geq$ $10 \mathrm{~cm} / \mathrm{s}$ ) was found in $152 \mathrm{GSVs}$ with a mean width of anechogenous lumen of $6.39 \mathrm{~mm}$ (minimum $2.7 \mathrm{~mm}$, maximum $13.0 \mathrm{~mm}$ ), median $6.0 \mathrm{~mm}, \mathrm{SD} \pm 2.21 \mathrm{~mm}$. No haemodynamically significant reflux was found in 48 GSVs. In the latter group, the mean width of anechogenous lumen was $4.41 \mathrm{~mm}$ (minimum $2.5 \mathrm{~mm}$, maximum $6.8 \mathrm{~mm}$ ), median $4.4 \mathrm{~mm}, \mathrm{SD} \pm 0.96 \mathrm{~mm}$ (Table 1). The difference between upper quartiles of width of GSV lumens with haemodynamically significant reflux and without reflux was statistically significant $(\mathrm{p}<0.01)$; the difference between lower quartiles was statistically significant $(\mathrm{p}<0.05)$. The difference in the mean width of the GSV of both groups was also statistically significant $(\mathrm{p}<0.01)$ (Table 1, Chart 1).

The width of the anechogenous lumen $<5 \mathrm{~mm}$ was measured in 77 GSVs ( $38.5 \%$ ) and lumen of $\geq 5 \mathrm{~mm}$ was found in $123 \mathrm{GSVs}(61.5 \%)$. In GSVs with a diameter of $<5 \mathrm{~mm}$, haemodynamically significant reflux (Vmax $\geq 10$ $\mathrm{cm} / \mathrm{s}$ ) was found in 46 cases (59.7\%). In GSVs dilated to $\geq 5 \mathrm{~mm}$, haemodynamically significant reflux was confirmed in 106 cases (86.2 \%) (Table 2).

Sensitivity of a GSV dilation of $\geq 5 \mathrm{~mm}$ for the presence of haemodynamically significant reflux in the SFJ was $69.7 \%$. Specificity of the GSV dilation of $\geq 5 \mathrm{~mm}$ for the presence of hameodynamically significant reflux in the SFJ was $64.6 \%$. Positive predictive value of the GSV dilation of $\geq 5 \mathrm{~mm}$ for the presence of haemodynamically significant reflux in the SFJ was $86.2 \%$, negative predictive value was $40.3 \%$, and diagnostic accuracy of the GSV dilation of $\geq 5 \mathrm{~mm}$ for the presence of hameodynamically significant reflux in the SFJ was $68.5 \%$.

\section{DISCUSSION}

Primary varicose veins of lower extremities are characterized by progressive worsening of valve function and dilation of the venous lumen. The most frequent finding in non-complicated (stage C1-3 according to CEAP) and complicated (stage C4-6 according to CEAP) varicose veins is SFJ and GSV trunk insufficiency - $68 \%$ and 83 $\%$, respectively, of lower the extremities ${ }^{14}$. SFJ incompetence predominates in primary as well as in recurrent varices $^{17}$.

According to our clinical experience and the literature, the normal width of the GSV below the groin does not exceed 5-6 $\mathrm{mm}\left(\mathrm{ref}^{8}{ }^{8}\right.$. Varicose veins have, in comparison with normal veins, a greater diameter of the lumen and hypertrophy of venous wall, particularly intima. This is due to increased collagenous fibre ${ }^{16}$. In an extensive prospective study including 612 lower extremities with GSV trunk varices, the mean width of the GSV with reflux in the thigh ( $88 \%$ ) was $5.75 \mathrm{~mm}$, the mean width of the GSV without reflux (12\%) was $4.98 \mathrm{~mm}\left(\right.$ ref. $\left.^{15}\right)$. In our work the boundary value of the width of anechogenous GSV lumen (to assess SFJ insufficiency) was $5 \mathrm{~mm}$. The mean width of insufficient GSV in our set $(n=152)$ was greater than reported by Sadouni et al., i.e. $6.39 \mathrm{~mm}$ (SD $\pm 2.21 \mathrm{~mm}$ ) (Table 1).

PW Doppler sample location was distal to the termination of the saphenous junctional tributaries, below the preterminal valve, in order to assess the function of the SFJ. The preterminal valve is located $3-5 \mathrm{~cm}$ below the terminal valve, distal to the termination of junctional tributaries to the GSV, to prevent reflux from the veins when the terminal valve is closed $^{3,4}$.

The reflux in SFJ was assessed in the course of Valsalva manoeuvre according to the maximum velocity of the backflow (Vmax) measured by PW Doppler 4-5 $\mathrm{cm}$ below the termination of the GSV to the common femoral vein because the velocity of reflux and the volume of the regurgitating venous blood corresponded both to the clinical grade of venous insufficiency and the scope of the reflux. In contrast, the reflux duration does not correspond to the clinical grade of chronic venous insufficiency according to the CEAP (ref. ${ }^{5}$ ), nor to the scope of reflux ${ }^{13}$.

In our set of $200 \mathrm{GSV}$ the difference between the upper and lower quartiles of lumen width of GSVs with haemodynamically significant reflux and those without reflux was statistically significant $(p<0.01$ resp. $p<0.05)$ (Table 1). The difference in mean width of the GSVs of both groups was also statistically significant $(p<0.01)$. However, the sensitivity of dilation of the GSV $\geq 5 \mathrm{~mm}$ below the groin due to haemodynamically significant re- 
Table 1. Statistical comparison of widths of anechogenous lumens of the GSV without reflux and the GSV with haemodynamically significant reflux in the SFJ

\begin{tabular}{|c|c|c|c|c|c|}
\hline & $\begin{array}{c}\text { Max. width } \\
(\mathrm{mm})\end{array}$ & $\begin{array}{c}\text { Min. width } \\
(\mathrm{mm})\end{array}$ & $\begin{array}{c}\text { Mean width } \\
(\mathrm{mm})\end{array}$ & $\begin{array}{c}\text { Median } \\
(\mathrm{mm})\end{array}$ & $\begin{array}{c}\text { SD } \pm \\
(\mathrm{mm})\end{array}$ \\
\hline $\begin{array}{c}\text { GSV with haemodyn. } \\
\text { significant reflux } \\
(\mathrm{n}=152)\end{array}$ & 13 & 2.7 & 6.39 & 6.0 & 2.21 \\
\hline $\begin{array}{c}\text { GSV without haemodyn. } \\
\text { significant reflux } \\
(\mathrm{n}=48)\end{array}$ & 6.8 & 2.5 & 4.41 & 4.4 & 0.96 \\
\hline $\mathrm{p}$ Value & $\mathrm{p}<0.01$ & $\mathrm{p}<0.05$ & $\mathrm{p}<0.01$ & $\mathrm{p}<0.01$ & \\
\hline
\end{tabular}

Table 2. Haemodynamically significant reflux in the SFJ (Vmax. $\geq 10 \mathrm{~cm} / \mathrm{s}$ ) and the width of the anechogenous GSV lumen in the groin

\begin{tabular}{|c|c|c|}
\hline \multirow{2}{*}{$\begin{array}{c}\text { Width of the anechogenous } \\
\text { lumen of the GSV }\end{array}$} & \multicolumn{2}{|c|}{ Reflux in the SFJ (Vmax. $\geq 10 \mathrm{~cm} / \mathrm{s})$} \\
\cline { 2 - 3 } & present & not present \\
\hline$\geq 5 \mathrm{~mm}$ & 106 legs & 17 legs \\
\hline$<5 \mathrm{~mm}$ & 46 legs & 31 legs \\
\hline
\end{tabular}

flux in the SFJ was not high (69.7\%). Measurement of the width of anechogenoue lumen of GSV in B-mode does not recognize about $30 \%$ of lower extremities with significant reflux in the SFJ. This implies that about one third of the GSVs, with a width below the groin not exceeding $5 \mathrm{~mm}$ - in ultrasonic scanning in B-mode, is affected by haemodynamically significant reflux in SFJ, confirmed by PW Doppler. Dilation of the GSV $\geq 5 \mathrm{~mm}$ below the groin was less specific (64.6\%). Therefore, between the GSVs with anechogenous lumen $<5 \mathrm{~mm}$ we will find about $35 \%$ with significant reflux in the SFJ.

The positive predictive value of the width of anechogenous lumen GSV $\geq 5 \mathrm{~mm}$ below the groin was relatively high $(86.2 \%)$. If GSV $\geq 5 \mathrm{~mm}$ is confirmed, there is a probability of $86.2 \%$ that the duplex scanning proves haemodynamically significant reflux in the SFJ. In contrast, the negative predictive value of dilation of the GSV $\geq 5 \mathrm{~mm}$ was very low (40.3\%). Hence, if a dilation of the $\mathrm{GSV} \geq 5 \mathrm{~mm}$ below the groin in B-mode is not found, then there is only $40.3 \%$ probability that the SFJ is functional and the duplex scanning will not prove haemodynamically significant reflux. The diagnostic accuracy of dilation of the GSV $\geq 5 \mathrm{~mm}$ is $68.5 \%$. This means that in approx. $70 \%$ of the GSV $\geq 5 \mathrm{~mm}$ haemodynamically significant reflux in SFJ is present.

The difference between GSVs without reflux and those with haemodynamically significant reflux was statistically significant ( $\mathrm{p}<0.05$, and $\mathrm{p}<0.01$ ) for maximum, minimum and mean width of anechogenous lumen (Table 1). However, the results show that for the diagnosis of hameodynamically significant reflux in the SFJ, measurement of the width of the anechogenous lumen of the GSV be-
Chart 1. Comparison of the mean width ( $\mathrm{mm})$ of anechogenous lumen of GSV without reflux (GSVrefl-) with reflux (GSVrefl+)

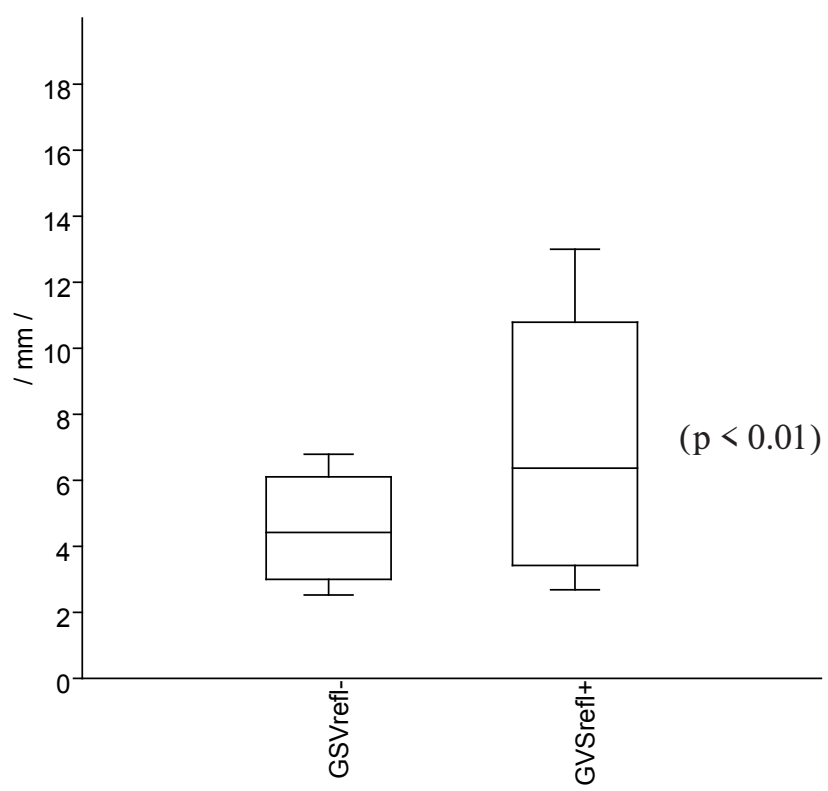

low the groin is insufficiently sensitive $(69.7 \%)$, as well as insufficiently specific (64.6\%). Only $68.5 \%$ of the all measurements of width of the GSV below the groin in B-mode provided accurate indirect assessment of the functions of valves in the SFJ.

In a patient the finding of dilated the GSV $\geq 5 \mathrm{~mm}$ below the groin means a $86.2 \%$ probability that the duplex 
scanning will confirm haemodynamically significant reflux in SFJ. The finding of non-dilated the GSV $<5 \mathrm{~mm}$ below the groin shows only $40.3 \%$ probability that the SFJ is functional and without haemodynamically significant reflux. Therefore, ultrasound scanning of the width of anechogenous lumen of the GSV below the groin (B-mode) may serve only as an orientation examination to assess the function of valves in SFJ. Only the duplex scanning (PW Doppler) can answer the question whether there is haemodynamically significant insufficiency of the SFJ.

\section{REFERENCES}

1. Baker SR, et al. Comparison of venous reflux assessed by duplex scanning and descending phlebography in chronic venous disease. Lancet 1993; 341:400.

2. Caggiati A, et al. Nomenclature of the veins of the lower limbs: An international interdisciplinary consensus statement. J Vasc Surg. 2002, 36, p. 416-422.

3. Caggiati A, et al. Nomenclature of the veins of the lower limb: Extensions, refinements, and clinical application. J Vasc Surg. 2005, 41, p. 19-724.

4. Cappelli, M, Molino Lova, R, Ermini, S, Zamboni, P. Hemodynamics of the saphena-femoral junction. Int Angol. 2004; 23:25-28.

5. Consensus statement. Classification and Grading of Chronic Venous Disease in the Lower Limbs: A Consensus Statement. Phlebology 1995; 10:42-45.
6. Eberhardt RT, Raffetto JD. Chronic venous insufficiency. Circulation 2005; 111:2398-2409.

7. Goren G, Yellin AE. Primary varicose veins: topographic and hemodynamic correlations. J Cardiovasc Surg 1990; 31:672-677.

8. Hennerici M, Neuerburg-Heusler D. Vascular diagnosis with ultrasound. Thieme, Stuttgart, New York, 1998.

9. Jutley RR, Cadle I, Cross KS. Preoperative investigation of the primary varicose veins. Eur J Vasc Endovasc Surg 2001; 21:370373.

10. Labropoulos N, Leon M, Nicolaides AN, et al. Superficial venous insufficiency: correlation of anatomic extent of reflux with clinical symptoms and signs. J Vasc Surg 1994; 20:953-958.

11. Lagattolla NRF, Donald A, Lockhart S, Burnand KG. Retrograde flow in the deep veins of subjects with normal venous function. $\mathrm{Br}$ J Surg 1997; 84:36-39.

12. Lurie F, Kistner RL, Eklog B: The mechanism of venous valve closure and role of the valve in circulation: a new concept. J Vasc Surg 2003; 38:955-961

13. Neglen P, Egger JF, Olivier J, Raju S. Haemodynamic and clinical impact of ultrasound-derived venous reflux parameters. J Vasc Surg 2004; 40:303-310.

14. Saarinen J et al. Symptoms, clinical disability score and reflux in complicated and non-complicates primary varicose veins of the lower limbs. Plebology 2003; 18:73-77.

15. Sadoun S, Benigni JP, Sica M. Prospective study of sclerosing foam in the treatment of truncal varices of the lower limbs. Plébologie 2002; 55:259-262.

16. Wali MA, Eid RA. Changes of elastic and collagen fibros in varicose veins. Intern Angiol. 2002; 21:337-343.

17. Wong JKF, Ducan JL, Nichols DM. Whole-leg duplex mapping for varicose veins: observations on patterns of reflux in recurrent and primary legs, with clinical correlation. J Vasc Endovasc Surg. 2003; 25:267-275. 